\title{
Pan-Canadian strategy being developed to tackle mental health in prisons
}

Published at www.cmaj.ca on Nov. 9

$\mathrm{F}$ ederal and provincial correction services have teamed up to draft a pan-Canadian correctional mental health strategy in the hope of improving the continuum of care for mentally ill offenders.

Correctional facilities have long been known to contain many more people with serious mental health problems than the general population. However, poor communication within Canada's multijurisdictional correctional system has posed a barrier to effectively delivering mental health services to offenders.

"Canadian penitentiaries are becoming the largest psychiatric facilities in the country," says Correctional Investigator of Canada Howard Sapers. "We're all dealing with essentially the same people, no matter what jurisdiction, but huge barriers exist in identifying and treating mental illness among offenders simply because we deliver care in silos and do not collect information in a way that makes it shareable."

The Correctional Service of Canada provides mental health care to offenders sentenced to two or more years in prison, while provincial or territorial services care for all those sentenced up to two years less a day. However, offenders with mental health problems are often caught in a "revolving door" between the community, provincial-territorial and federal correctional facilities.

"While corrections at both the provincial and federal level are doing an increasingly better job of identifying the needs of mentally ill inmates in their jurisdictions, without an integrated plan we see huge disruptions in medical care and follow up, huge disruptions in medication, every time they transition from one environment or facility to another," says Sapers. "That makes treatment ineffective and has been doing very little to address the need we are becoming so good at identifying."

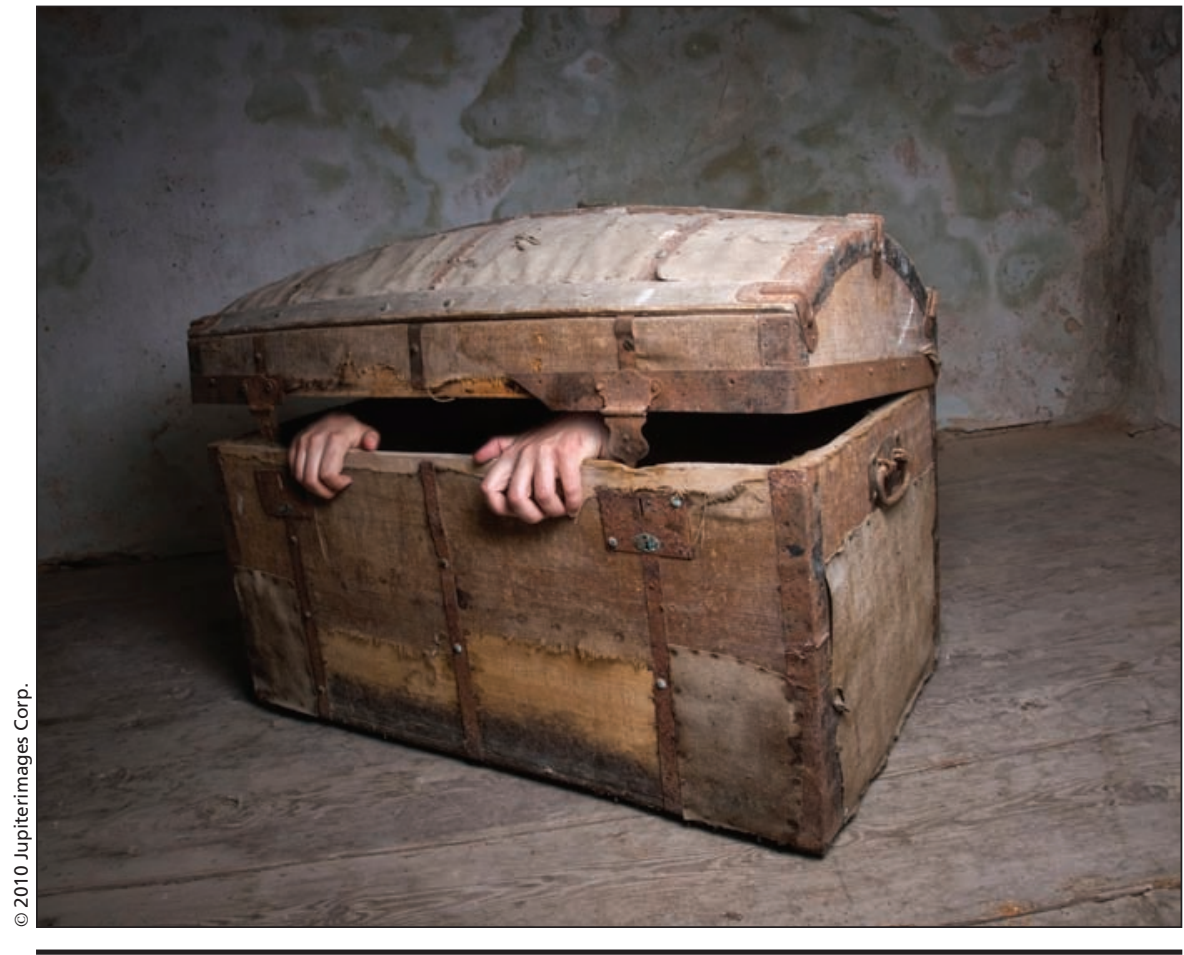

Jurisdictional wrangling often leaves prisoners with mental problems feeling trapped and without access to mental health services.

A pan-Canadian correctional mental health strategy will attempt to bridge the jurisdictional no man's land between services by sharing tools and best practices between federal and provincialterritorial authorities.

A framework for implementing the mental health strategy was hammered out by the Correctional Service of Canada, provincial and territorial correctional services, the Mental Health Commission of Canada and the Parole Board of Canada in October.

"There's no one solution that will equally address all the gaps that exist, because we each have our own challenges and opportunities," says Jennifer Wheatley, director of general performance management for the federal correctional service. "What we're trying to do instead is match those jurisdictions with strengths in certain areas to those with weaknesses in the same areas so we can share tools and learning without having to recreate the wheel.'

The strategy will tackle gaps in screening, transition services and training for correctional staff in a bid to improve early detection and treatment of mental health problems. It's hoped that it will also help to ensure that progress made in one setting is not lost when an inmate is moved to another facility or back into the community, as well as prevent stigmatization and mistreatment of mentally ill offenders.

The 2007 suicide of 19-year-old Ashley Smith revealed many of the gaps within the current system. Jailed for a series of minor offences, Smith spent 2003 to 2006 in two New Brunswick correctional facilities before ending up in an Ontario federal women's prison, where she strangled herself under the watch of guards.

The case, and the later release of a 
video of guards pepper spraying Smith in her cell, drew widespread criticism of how the prison system handles mentally ill offenders. In the probe that followed, both Sapers and the New Brunswick correctional investigator called for the implementation of a national mental health strategy for corrections.

Several other countries already have similar strategies in place, including Australia and Denmark, says Wheatley. "But the primary difference is that none of those strategies deal with the same jurisdictional issues Canada faces."

Sapers is pleased the development of the pan-Canadian strategy is underway, but is anxious that it be implemented sooner than later. In a recent report, he called on the federal correctional service to "establish clear guidelines, timeframes and governance structures for implementation by the end of 2012" (www.oci-bec.gc.ca/rpt/oth-aut /oth-aut20100923-eng.aspx).
Wheatley declined to comment on when the strategy might be implemented. She says jurisdictions are looking for ways to collaborate in the short term, and have already shared training materials.

Sapers' review of the strategy's development is expected to be tabled in Parliament later this fall. - Lauren Vogel, CMAJ

DOI:10.1503/cmaj.109-3722 